\title{
PRESERVAÇÃO DAS FACES E TEORIA DA POLIDEZ NAS INTERAÇÕES DISCURSIVAS EM COMENTÁRIOS AVALIATIVOS DO GOOGLE MAPS, ACERCA DE BARES TERESINENSES.
}

\author{
PRESERVATION OF FACE AND POLITENESS THEORY IN DISCURSIVE \\ INTERACTIONS IN GOOGLE MAPS EVALUATIVE COMMENTS ABOUT BARS \\ IN TERESINA.
}

\author{
Recebido: 18/03/2020 | Aprovado: 18/05/2020 | Publicado: 10/07/2020 \\ DOI: https://doi.org/10.18817/rlj.v4i1.2151
}

\begin{abstract}
lara Silva de Souza ${ }^{1}$
Orcid ID: https://orcid.org/0000-0002-8177-300X
\end{abstract}

\begin{abstract}
Resumo: Este trabalho objetiva analisar as interações em comentários avaliativos da plataforma Google Maps, na perspectiva das estratégias de polidez e preservação das faces. Para tanto, iremos nos apoiar nos estudos de Brown e Levinson (1987) que abordam as noções das faces, complementando os estudos do sociólogo Goffman (1967) no que concerne as estratégias de ameaça e preservação das faces dos interlocutores, e também iremos tomar por base as estratégias de polidez que Brown e Levinson elencam. Iremos discorrer sobre a possível definição do termo pragmática, resgatando a noção de interação verbal, buscando associá-la aos estudos das faces e as estratégias de polidez ao longo do artigo. Sobre os resultados obtidos das análises, a conclusão que se chega é de que os representantes que falam em nome do estabelecimento, ora buscam romper e salvar a todo instante algumas faces, em um intuito específico, ou em prol do bem-estar do cliente, atribuindo-Ihe razão, ora tiram-Ihe a razão, com o objetivo de salvar a sua imagem positiva enquanto estabelecimento comercial. Esse jogo de interação entre locutor e interlocutor recai sobre a preservação da imagem, que se constrói nas relações entre os participantes que vão sendo estabelecidas e isso necessita de uma preservação das faces e das estratégias de polidez em qualquer contexto de comunicação e interação.
\end{abstract}

Palavras-chave: Interação. Preservação das faces. Estratégias de polidez.

\begin{abstract}
This work aims to analyze the interactions in Google Maps evaluative comments, from the perspective of the strategies of politeness and preservation of faces. For this purpose, we will rely on the studies of Brown and Levinson (1987) that approach the notions of faces, complementing the studies of the sociologist Goffman (1967) concerning the strategies of threat and preservation of the faces of interlocutors, and our study was based on the strategies of politeness that was listed by Brown and Levinson. We will discuss about the possible definition of the term pragmatic, rescuing the notion of verbal interaction, trying to associate it to the studies of faces and the strategies of politeness throughout the article. Concerning the results obtained from the analysis, we concluded that the representatives, who speak on behalf of the establishment, sometimes seek to break and save some faces at all times for a specific purpose or for the welfare of the client, attributing reason to it, sometimes they take away the reasons in order to save their positive image as a commercial establishment. This game of interaction between speaker and interlocutor favors the preservation of their image, which is built on the relationships between the participants that are being established and this requires a preservation of the faces and strategies of politeness in any context of communication and interaction.
\end{abstract}

Keywords: Interaction. Preservation of faces. Strategies of politeness.

\footnotetext{
${ }^{1}$ Mestranda do programa de pós-graduação em Letras da Universidade Federal do Piauí- UFPI (biênio 2019-2021). Graduada em Letras Português pela UFPI, membro do Núcleo de Estudo e Pesquisas em Análise do Discurso (NEPAD- UFPI), desenvolvendo pesquisas relacionadas às representações sociais, ethos e discurso literário. E-mail: iarasilva@ufpi.edu.br
} 


\section{INTRODUÇÃO}

É inegável a grande influência e participação da internet no âmbito social, nisso, se faz presente a abertura para a atuação ativa e crítica da sociedade, juntamente com possiblidade de interação com outros sujeitos, criando-se um emaranhado de ideias que conversam entre si. Tomando a língua como um elemento dinâmico e interativo, um campo rico para os estudos pragmáticos, este artigo objetiva identificar e compreender as estratégias de polidez que se encontram nas interações de internautas em comentários avaliativos no Google Maps, em alguns bares em Teresina, focalizando as ameaças e proteção das faces desses estabelecimentos, como também a relação proprietário-cliente na solução de conflitos, observando as atitudes responsivas dessas interações virtuais.

A pragmática se interessa pela comunicação verbal, observando a organização dos grupos sociais e seus modos de utilização real da língua, desde o plano textual ao discursivo. A partir dessas relações sócio interativas, surgem estratégias no uso da língua, com o objetivo de ter uma boa convivência social, atenuação de conflitos, preservar o espaço do outro e a sua integridade moral. Essas interações serão analisadas à luz das estratégias de polidez, através dos estudos feitos por Brown e Levinson (1987) integrada à noção "das faces" do sociólogo Goffman (1967) que revela as estratégias de ameaça e preservação das faces. $O$ intuito das abordagens a serem realizadas nesse artigo é mostrar as importantes contribuições para o sucesso nas interações sócio discursivas e convivência social dos sujeitos falantes. Diante do exposto, a priori, o objetivo deste trabalho é identificar as estratégias de preservação das faces e polidez nas relações interativas detectadas entre os proprietários e clientes de dois bares localizados na cidade de Teresina-PI, observados em comentários no aplicativo Google Maps.

\section{A PRAGMÁTICA}

O termo pragmática é de difícil definição, que vai além da estrutura formal e semântica do signo linguístico, abarcando o contexto como sua base, os 
participantes da interação, suas intenções no âmbito comunicativo, as reações do seu interlocutor. Essa definição não é satisfatória para um campo tão amplo como é a pragmática, mas serve como uma indicação do que permeia os estudos pragmáticos.

Stephen Levinson (2007) mostra que o termo pragmática surgiu em uma divisão da semiótica realizada por Morris, em que há a abordagem dos diversos fenômenos psicológicos e sociológicos que envolvem o sistema linguístico e até na linguagem em particular. Levinson também aponta um dos sentidos da pragmática de Carnap, o qual remete aos conceitos abstratos que se referiam aos agentes, também faz menção aos estudos dos dêiticos, feitos por Montague, e o mais recente uso na linguística e na filosofia anglo americana. $O$ autor se detém fielmente na última divisão, com o intuito de uma tentativa de definição do que vem a ser pragmática.

Levinson (2007, p.29) assevera que o que deve ser feito é encarar a pragmática como "o estudo da capacidade dos usuários da língua de emparelhar sentenças com os contextos em que elas seriam adequadas". Ou seja, é preciso considerar as sentenças bem formadas da língua, como combinações sintáticas, considerando suas expressões semânticas que as designam, juntamente com o contexto adequando a esses elementos. Ainda a respeito sobre esse fato, o autor comenta que

Na verdade, num certo sentido, não há absolutamente nenhum problema de definição: assim como, tradicionalmente, a sintaxe é considerada o estudo das propriedades combinatórias das palavras e suas partes, e a semântica o estudo do significado, a pragmática é o estudo do uso linguístico. (LEVINSON, 2007, p.6).

Os estudos pragmáticos se ancoram na filosofia e linguística, mas a definição do termo pragmática, para alguns estudiosos como Lyons e Searle, conforme Levinson, é considerada incerta e obscura. Destarte, os estudiosos da pragmática desempenham a tarefa de expor que "o termo realmente tem aplicação clara" (LEVINSON, 2007, p.7). Outra definição que o autor faz acerca dessa corrente, é a sua perspectiva funcional do estudo da linguagem, em uma tentativa de explicar as facetas da estrutura dos signos, por pressões externas e não linguísticas, mas como ele retifica, essa definição não distinguiria a pragmática 
linguística das demais disciplinas que envolvam as abordagens funcionais da linguística. Após essa breve discussão, iremos tomar como base a essência da pragmática no uso linguístico, ancorada em elementos linguísticos que compõem a interação entre interlocutores, iremos abordar o conceito de interação verbal e suas implicações no uso das faces dos falantes e suas estratégias de polidez em contextos específicos.

\title{
INTERAÇÃO VERBAL
}

A interação verbal comporta uma importância fundamental no uso da linguagem, na qual os enunciados conversam entre si, sendo eles verbais ou nãoverbais. A concretude da língua se faz presente no ato de enunciar, tornando-se fruto de uma relação dos falantes de determinada comunidade de fala. Nisso, Bakhtin (1995) revela essa importância, tomando a produção desses enunciados como um fenômeno social:

A verdadeira substância da língua não é constituída por um sistema abstrato de formas linguísticas nem pela enunciação monológica isolada, nem pelo ato psicofisiológico de sua produção, mas pelo fenômeno social da interação verbal, realizada através da enunciação ou das enunciações. A interação verbal constitui assim a realidade fundamental da língua. (BAKHTIN, 1995, p.125).

A substância da língua está além de um sistema de estruturas linguísticas, pois a língua em si é caracterizada pelo seu teor social e interativo, sendo este constituinte da língua propriamente dita. A palavra em sua verdadeira autonomia comporta um poder muito grande em relação aos elementos necessários à comunicação, a palavra é o produto do diálogo, indispensável na relação comunicativa que se dá na interação entre locutor e interlocutor. Bakhtin (1995) salienta que

\begin{abstract}
A palavra é uma espécie de ponte lançada entre mim e os outros. Se ela se apoia sobre mim numa extremidade, na outra apoia-se sobre o meu interlocutor. A palavra é o território comum do locutor e do interlocutor. " Frisando a importância de outrem na produção de enunciados, deixando explícita a mútua dependência do locutor e do interlocutor no processo de interação verbal. (BAKHTIN,1995, p. 115).
\end{abstract}

A língua é empregada em forma de enunciados concretos, sendo exercida por integrantes de qualquer campo de atividade humana. Cada enunciado tem uma 
carga significativa bastante relevante em relação à finalidade dos enunciados proferidos, refletindo as condições e finalidades de cada campo no momento enunciativo. Em Bakhtin (2003) percebemos três elementos essenciais para a constituição de um enunciado:

O conteúdo temático, o estilo, a construção composicional, estão indissoluvelmente ligados no todo do enunciado e são igualmente determinados pela especificidade de um determinado campo da comunicação (BAKHTIN, 2003, p.262).

Ou seja, para a finalidade de cada campo enunciativo o enunciado não precisa ser meramente linguístico, mas visto pela sua construção composicional, fazendo com que se tenha um olhar além da língua. Essa organização composicional da língua abre espaço para a emergência do gênero discursivo, sendo concebido por uma visão sociológica da língua, sendo uma noção norteadora do interacionismo verbal no uso concreto da linguagem. Ainda sobre o aspecto interacional da linguagem, percebe-se o caráter responsivo nessa dimensão discursiva da linguagem, no qual os enunciados se inter-relacionam de forma responsiva, contribuindo para a formação da atividade sócio interativa. Dessa forma, todo enunciado é sempre proveniente de alguém e direcionado para outrem, em uma relação que se faz necessário uma reposta:

Essa orientação da palavra em função do interlocutor tem uma importância muito grande. Na realidade toda palavra comporta duas faces. Ela é determinada tanto pelo fato de que procede de alguém, como pelo fato de que se dirige para alguém. Ela constitui justamente o produto da interação entre o locutor e o ouvinte. (BAKHTIN, 1995, p. 113).

Nesse jogo responsivo, encontra-se o constante diálogo dessa interação vinculado com as relações e papéis sociais, tornando o signo um elemento constituído por uma dupla determinação, com basicamente dois seres participantes da comunidade linguística: o locutor e ouvinte, que são responsáveis pelas tomadas de palavra. O ouvinte age respondendo algo que foi dito anteriormente por seu locutor, em um processo interno discursivo, proveniente de suas práticas sociais e experiências vividas.

No contexto da enunciação, os interlocutores procuram possibilidades de resposta e esses enunciados que circulam no âmbito social e que são dirigidos a 
eles. A resposta dada, como percebe-se, irá depender basicamente da situação em que o enunciado é produzido, e dos papéis sociais que ocupam os parceiros desse processo, compartilhando não só palavras, mas um lugar comum, em que os sentidos possam ser compreendidos e suas experiências partilhadas.

\section{O ESTUDO DAS FACES E O OLHAR PARA O OUTRO}

Iniciando a discussão dos estudos das faces, é importante frisar que a teoria da polidez se relaciona com o processo de elaboração da face, ou seja, a autoimagem pública dos indivíduos. Na definição de face, Goffman coloca que ela corresponde ao "Valor social positivo que uma pessoa efetivamente reclama para si mesma através daquilo que os outros presumem ser uma linha por ela tomada durante um contato específico" (GOFFMAN, 1980: 77).

Dito isso, é evidente que a face elaborada pelo indivíduo, servirá para as situações sociais e interacionais, havendo a necessidade da utilização de habilidades e/ou condutas atenuantes. Goffman (1967) aponta elementos mantenedores e ameaçadores à face. Vejamos: os elementos mantenedores da face são o orgulho, honra e dignidade. Já os elementos ameaçadores da face são constituídos por gafes, insultos maliciosos e ofensas. Assim, Goffman aborda que a face social dos indivíduos, por mais pessoal que seja, ela acaba por corresponder à convenções e regras da sociedade, havendo, então, a necessidade de preservação da face como um princípio autorregulador para um equilíbrio das relações sociais.

Dando continuidade aos trabalhos da face, Brown e Levinson (1987) sistematizam os estudos sobre a face na teoria da polidez. Partindo da noção de autoimagem de Goffman, eles mostraram os dois elementos que contribuem com a imagem do "eu" (self) construída no meio social, que são a face positiva e a face negativa. Retomando as ideias de Goffman, os autores ampliaram a noção de face, configurando-as dessa forma: a face positiva, que diz respeito ao anseio do ser humano de ser aprovado, reconhecido, admirado, valorizado, aceito, a partir dos seus desejos, opiniões, atitudes, de ser importante e especial, a face positiva sendo elaborada como uma fachada social. A face negativa relaciona-se com o desejo de não haver imposição, invasão de sua liberdade de ação e do território íntimo, ou 
seja, o desejo de não ser incomodado e/ou pressionado. A respeito disso, Maingueneau assevera que no ato da enunciação essas duas faces podem ser colocadas em xeque, ou seja:

\begin{abstract}
Todo ato de enunciação pode constituir uma ameaça para uma ou várias dessas faces: dar uma ordem valoriza a face positiva do locutor, desvalorizando a do interlocutor; dirigir a palavra a um desconhecido ameaça a face negativa do destinatário (é uma intrusão no seu território), mas também a face positiva do locutor (que pode ser visto como sendo excessivamente desinibido) " (MAINGUENEAU, 2001, p. 38).
\end{abstract}

Dessa forma, levando em consideração o envolvimento de pelo menos quatro faces durante a interação(duas do falante e duas do ouvinte), os atos ameaçadores da face podem se dividir em quatro tipos: atos que ameaçam a face positiva do interlocutor, como críticas, insultos, reclamações, acusações, desaprovações, recusas, etc.; atos que ameaçam a face negativa do interlocutor, que se caracterizam como as ordens, pedidos, ameaças, perguntas indiscretas, advertências, avisos, conselhos, proibições e afins; atos que ameaçam a face positiva do locutor, como pedidos de desculpa, reconhecimentos de erros, confissões, auto humilhações, autocríticas, etc.; e por último, atos que ameaçam a face negativa do locutor, que seria aceitar uma oferta, a promessa, que vai comprometer o sujeito a avaliar a competência alheia, atos de julgamentos, uma aplicação de feedback, aceitação de favor, agradecimentos, etc.

Diante disso, surge também, os atos ameaçadores da face negativa e positiva dos integrantes da situação de comunicação, como por exemplo: ameaçar o outro, humilhá-lo, insultá-lo, interrompê-lo, fazer perguntas pessoais, sendo atitudes que se designam como atos ameaçadores às duas faces do interlocutor, como também são atos que ameaçam a face positiva do locutor. Nesse jogo de faces, há sempre o anseio de desmontar a face positiva do outro, a fim de revelar a sua imagem negativa, em uma atitude defensiva com a intenção de preservar sua própria face. Esse processo recebe o nome de face work, que são procedimentos que neutralizam as ameaças à face, ou seja, estratégias discursivas que tem como objetivo convencer, envolver, influenciar as decisões dos interlocutores

$\mathrm{Na}$ interação, também surge o interesse de preservar a face do outro, que consistem em satisfazer os desejos de outrem, que são permeados por recursos que irão satisfazer alguns desejos de face do alocutário, tornando brando o teor de 
ameaça dos atos ameaçadores de faces, esses recursos e estratégias de preservação são chamadas de polidez.

\section{TEORIA DA POLIDEZ}

É importante enfatizar que a teoria da polidez se relaciona com o processo de elaboração da face, ou seja, a autoimagem pública dos indivíduos. Victoria Wilson (2011) no capítulo Motivações pragmáticas, do livro Manual de linguística, comenta sobre o anseio da preservação da face do outro e intenção de atenuar o grau de ameaça à sua face, configurando assim, uma estratégia de polidez:

Toda vez que fazemos um pedido a alguém estamos ameaçando a face porque invadimos a privacidade da pessoa, por isso, em geral, os pedidos são feitos de modo a atenuar o grau de ameaça à face do outro (WILSON, 2011, p. 98).

Os estudos da polidez são introduzidos por Brown e Levinson (1987), oriundas do trabalho de Erving Goffman (1967), que desenvolveu trabalhos sobre face a partir do princípio da cooperação, proposto por Grice (1975). Pode-se dizer que a polidez é aplicada em um sentido bem abrangente no âmbito social, que a compreende como fórmulas de cortesia, regras de etiqueta, e estratégias utilizadas para minimizar conflitos que alguns atos de linguagem trazem para o momento da interação verbal. Para Brown e Levinson (1987), a polidez é encarregada por zelar pela ordem social, estabelecendo uma cooperação entre os indivíduos, configurando um complexo sistema de estratégias que colaboram para um maior distanciamento dos atos ameaçadores de face, que por sua vez, geram conflitos na interação comunicativa. Como afirma Wilson (2011):

Impregnada de carga afetiva, a face pode ser perdida, mantida ou
engrandecida em função de cada tipo de situação e está mais voltada às
necessidades de face do outro (...). O fenômeno da polidez- em princípio
universal- parece dar conta não só das relações sociais que estabelecem,
mas da maneira como eles ocorrem e se organizam. (WILSON, 2011, p.
100).

A partir disso, compreende-se que a polidez, constituída de norma sociais, irá prescrever explicitamente comportamentos, maneiras de agir, a fim de que haja um convívio harmonioso entre os sujeitos em determinadas situações. A polidez, 
considerada um fenômeno social, está presente em praticamente todas as situações de interação, apoiando-se em estratégias linguísticas.

Em tese, a comunicação implica, pelo menos dois parceiros, há sempre, no mínimo quatro faces em jogo, e todas com o mesmo objetivo: lidar com as possíveis ameaças da enunciação. Compreendendo a interação social como campo fértil para estratégias de polidez, Brown; Levinson (1987) defendem que esse que fenômeno sofre dois tipos de pressão: a de caráter comunicativo, que garantem a boa transmissão da mensagem a ser veiculada, e a pressão ritual, que garantem a preservação das faces dos sujeitos, estas vão influenciar bastante a estrutura do discurso. Esse processo do ritual visa amenizar as ameaças à face dos participantes da interação, influenciando o modo de realização enunciado, compostos por atitudes sutis que asseguram um bom uso da troca verbal, elaborando de forma eficiente a estrutura da troca comunicativa para o êxito da interação harmoniosa e livre de conflitos, com uma transmissão eficaz de informações, satisfazendo as faces que estão imergidas na situação do conflito em potencial.

Ainda sobre os autores Brown e Levinson (1978), eles listam algumas estratégias de polidez positiva, que recaem na face positiva do interlocutor. Esse tipo de polidez assegura satisfazer, em partes, as aspirações e desejos do ouvinte, nesse jogo, o locutor tem o papel de deixar explícito que há desejos comuns entre ele e seu interlocutor, com o intuito de estreitar a possível distância que ambos têm. As estratégias de polidez positiva são as seguintes: Perceba o outro; procure acordo; mostre-se interessado pelos desejos e necessidades do outro; pressuponha; declare pontos em comum; evite desacordo; faça piadas; ofereça; prometa; seja otimista; dê presentes; dê ou peça razões, explicações.

A polidez negativa é elaborada com o emprego de expressões que evitem imposições ao parceiro da interação, com um comportamento de caráter respeitoso e o não querer comprometer-se com o interlocutor. Esse tipo de polidez é bem mais limitado do que a polidez positiva, ela busca minimizar uma possível imposição na troca verbal dos falantes, pondo um limite social na situação de interação entre os sujeitos: impessoalize o falante e o ouvinte; questione; seja evasivo; seja pessimista; peça desculpas; mostre respeito; seja convencionalmente indireto. A polidez indireta é característica de uma atitude indireta, no qual o locutor evita 
responsabilidades, deixando nas mãos do ouvinte, as possíveis interpretações de suas ações indiretas. Essa estratégia prescreve as seguintes atitudes: forneça pistas; pressuponha; use tautologias; seja irônico; seja ambíguo; seja incompleto, use elipses, use contradições; faça perguntas retóricas.

\section{COMENTÁRIOS AVALIATIVOS: UMA PROPOSTA DE ANÁLISE}

A interação surge por meio de motivações, ou seja, o falante tem a opção de escolher os modos possíveis que pode atuar nela, visando os efeitos que pode causar. Essa escolha dos modos possíveis para atuar no ato comunicativo se faz presente nitidamente no corpus selecionado para esse artigo, no qual os participantes da situação comunicativa, selecionam elementos que são carregados de intencionalidades para produzir efeitos de sentido, utilizando ou não as estratégias de polidez ou a preservação de face dos parceiros para tal feito intencional.

O aplicativo Google Maps oferece um espaço destinado para avaliar um local, dar sugestões e críticas a respeito do ambiente visitado. Nisso, cabe ao proprietário a atitude de responder ou não essas manifestações da clientela. Com a resposta do proprietário, há uma interação evidente, pautada em preservar a integridade do seu estabelecimento e de seus gestores, bem como, atrair mais clientes com as respostas prestativas, polidas e bem-humoradas, mas também, eles podem utilizar da impolidez como um mecanismo de mostrar uma possível injustiça praticada contra seu estabelecimento. A presente pesquisa se configura de natureza qualitativa, na qual serão analisados fragmentos de algumas avaliações online acerca de dois bares localizados em Teresina-Pi. Para tanto, selecionamos alguns comentários localizados na página de cada estabelecimento feitos no ano de 2019. Pela média de avaliações dadas em formas de estrelas, nota-se que os dois estabelecimentos selecionados são referência da categoria de bares da cidade. A título de preservação da identificação dos bares nas análises, iremos nomeá-los de estabelecimento 1 e estabelecimento 2.

\section{Estabelecimento 1}


Iniciando as análises, no fragmento a seguir, temos a reação de uma reclamação proveniente de um cliente do estabelecimento. O comentário do consumidor consiste em pôr em ênfase o preço elevado do bar, tomando por base a falta de qualidade da comida que é oferecida no local, conforme podemos perceber na figura 1 :

Figura 1 - Exemplo de avaliação negativa e resposta constituída de estratégias de polidez a fim de se estabelecer uma aproximação do cliente

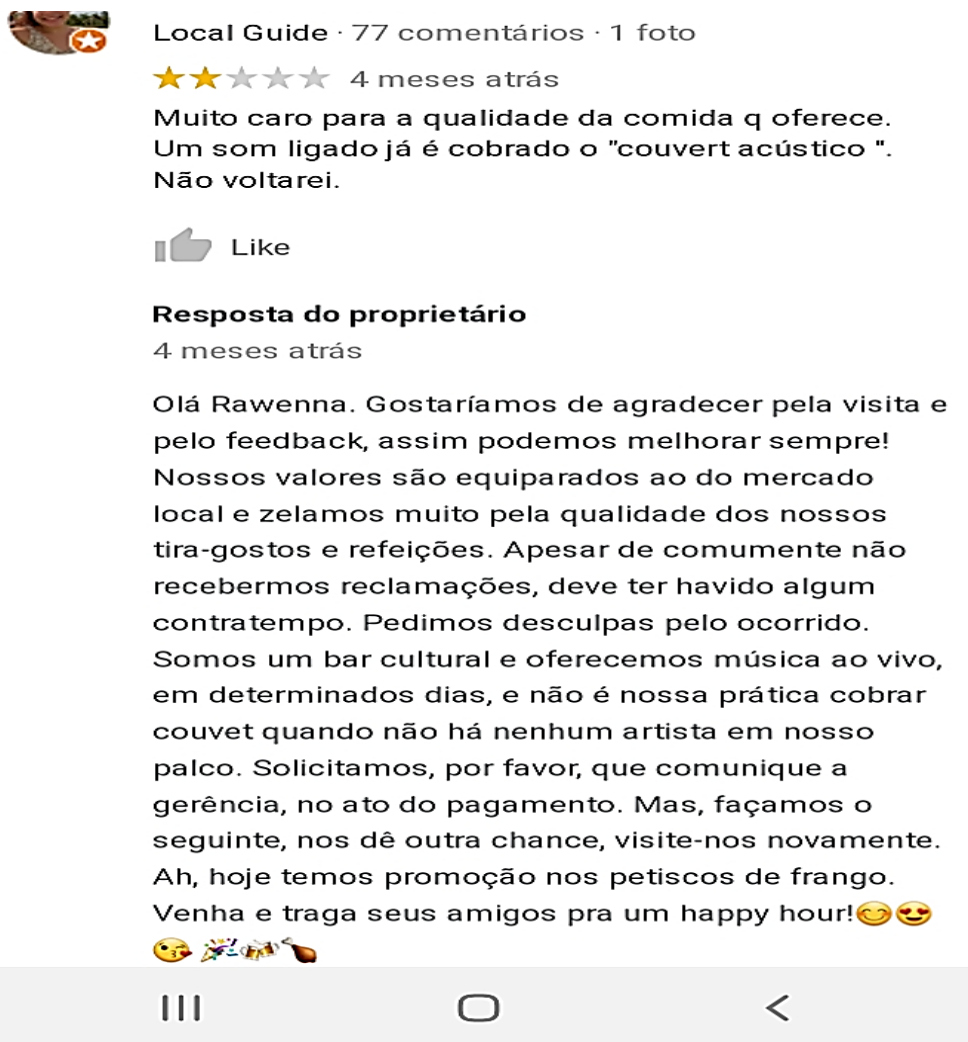

Fonte: Google (2019)

Pode-se observar que o comentário feito põe em jogo a face positiva do dono do estabelecimento, que por sua vez, se sentirá ofendido. Nesse caso, sua fachada social é prejudicada, já que ele enuncia a partir do estabelecimento. $\mathrm{Na}$ obrigação de resposta, em defesa da sua face positiva, o proprietário utiliza-se da polidez para atenuar o seu direcionamento ao cliente, a fim de manter a relação harmoniosa entre ele e o consumidor. O proprietário lança mão da saudação, dirigindo-se pelo nome da cliente, trazendo uma maior proximidade entre ambos. 
Sendo saudoso e amigável, ele demonstra interesse e simpatia pelo interlocutor, em seguida, agradece a visita que foi feita e o feedback que foi dado, ressaltando a importância do retorno feito acerca do serviço prestado, como um incentivo para estar sempre melhorando.

Após essa atenuação da introdução da resposta que foi elaborada, ele prossegue com as justificativas, de cunho mais objetivo, fazendo comparações com outros estabelecimentos, alegando que os preços não são exorbitantes como a cliente relatou, e que provavelmente houve um contratempo para que isso acontecesse, já que não é costumeiro esse tipo de reclamação. Após esse esclarecimento ele utiliza mais uma estratégia de polidez, que foi a de pedir desculpas pelo ocorrido. Vê-se que o proprietário utiliza a primeira pessoa do plural, assim, demarca a enunciação dele em nome da empresa: "Pedimos desculpa pelo ocorrido", "somos um bar cultural e oferecemos música ao vivo". Na resposta, ele pede um favor, configurando um ato que ameaçam a face positiva dele, como por exemplo, pedidos de desculpa, reconhecimentos de erros, autocríticas, lançando mão das estratégia de polidez positiva, que seriam manifestar a atenção ao interlocutor, exagerando na simpatia , mostrando um interesse pelo fato acontecido que envolveu seu cliente, evitando discordâncias, como prova disso, ele solicita a comunicação imediata com a gerência, para que o problema da cobrança imprópria seja resolvido o mais breve possível.

Concluindo o seu comentário, o proprietário, em nome da empresa, busca captar o cliente pelo pedido de uma outra chance: "nos dê uma segunda chance", ancorando-se em outra estratégia de polidez positiva, na busca de satisfazer seu cliente, procurando firmar um acordo ao tomar essa atitude. Em seguida, ele informa uma promoção que julga ser de interesse do cliente, almejando um possível retorno do mesmo. Nesse caso, o oferecimento da promoção objetiva oferecer uma recompensa ao cliente, como se o proprietário desse um presente, que se configura como outra estratégia de polidez. Logo adiante, nota-se um tom saudoso e bem convidativo e uma inserção de emoticons que revelam o caráter saudoso e polido da resposta, que acaba por trazer mais harmonia para a situação comunicativa que ambos se encontram. Em suma, o proprietário que estava envolto em situação de um possível conflito com o seu cliente, utilizou diversas estratégias de preservação 
das faces e polidez, buscando atenuar o diálogo e satisfazer, em partes, as aspirações e desejos do ouvinte.

No segundo fragmento, seguindo com as análises, temos outro exemplo da preocupação com a face do outro e do uso das estratégias de polidez que o dono do estabelecimento faz, quando se trata de responder às reclamações que a cliente manifesta. Vemos que o consumidor reclama do volume da música, da demora dos serviços prestados e o transtorno que passou, até chegar ao ponto de ir para outro estabelecimento:

Figura 2 - Avaliação negativa seguida de interação polida por parte do proprietário do estabelecimento

\section{$\star \star \star \star \star \star * t$ um mês atrás}

Música alta, demora para chegar comida e drinks.

Tivemos que cancelar os pedidos e ir para outro lugar.

\section{Like}

\section{Resposta do proprietário}

um mês atrás

Olá Thaiane. 0 que podemos fazer para melhorar a sua avaliação sobre nosso estabelecimento? Aguardamos a sua resposta aqui, ok?! Grande abraço!

Fonte: Google (2019)

O proprietário, de forma saudosa, se direciona à cliente pelo nome, querendo estabelecer uma certa proximidade, usando as estratégias de polidez positiva, percebendo o outro, mostrando interesse pela necessidade de outro, ele não fez o uso de perguntas diretas que pressionem o interlocutor, ou que o obrigue a oferecer uma resposta de imediato, evitando um conflito, pedindo sugestões para fornecer um serviço de melhor qualidade. Nesse exemplo de interação proprietáriocliente, surge o interesse de preservar a face do outro, que consiste em satisfazer os desejos do seu cliente, ou seja, usando recursos linguísticos que irão satisfazer 
alguns desejos de face do alocutário. O dono do estabelecimento busca minimizar uma possível imposição na troca verbal, mostrando respeito e cordialidade, solicitando as sugestões do cliente a respeito do bar, preservando a face negativa de seu interlocutor, em detrimento da sua face positiva. No final do comentário, 0 proprietário finaliza com "Grande abraço", sendo uma estratégia de distanciamento conflitual, que há um esforço do representante da empresa em estabelecer uma interação longe dos parâmetros conflituosos, deixando em evidência o teor cortês que têm suas respostas, no que diz respeito às reclamações feitas pelos clientes.

\section{Estabelecimento 2}

No fragmento selecionado do estabelecimento 2, a avaliação do cliente consiste em reclamar de uma série de fatores, como por exemplo, o atendimento que demorou, poucas opções de bebida, os preços e a precariedade da cozinha:

Figura 3 - Exemplo de interação impolida e ameaça da face negativa do cliente

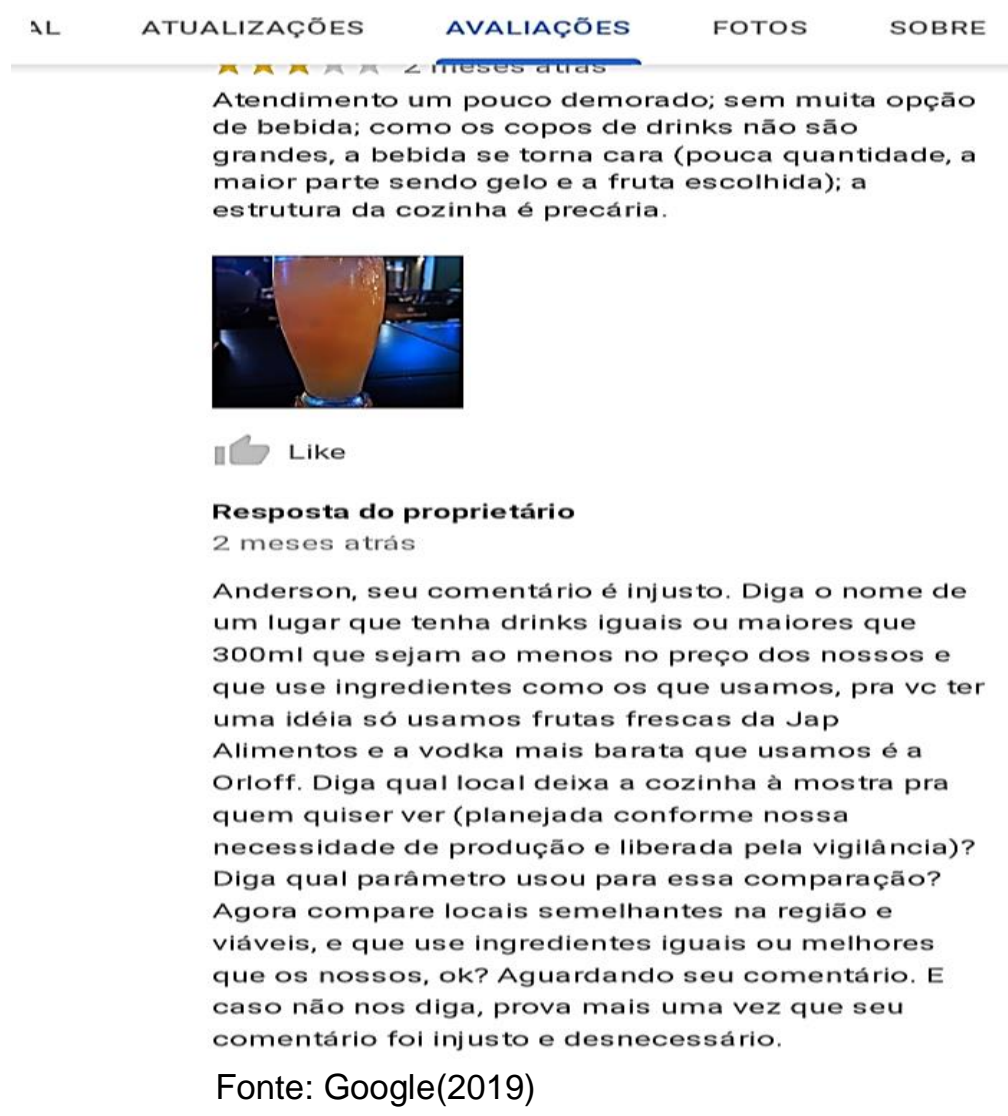


Em contrapartida, o representante alega que o comentário que foi feito pelo cliente é injusto, a partir disso, ele elenca várias perguntas diretas ao seu interlocutor, violando com a estratégia de polidez negativa, que serve para minimizar a imposição na troca verbal: "Diga qual local deixa a cozinha à mostra pra quem quiser ver", "Diga qual parâmetro usou para essa comparação? ", "Agora compare locais semelhantes na região e viáveis, e que use ingredientes iguais ou melhores que os nossos, ok?" "Aguardando seu comentário. " O uso dessas perguntas diretas deixa explícita a imposição feita para ter um posicionamento imediato do cliente, a todo momento ele exige uma resposta aos questionamentos que ele elencou, esse jogo de imposição, ameaça a face negativa do cliente, uma vez que houve uma invasão de território e o desrespeito do mesmo, a utilização de "diga", "compare", "ok" comprova o quão direto e impositivo e proprietário foi, além de não se desculpar pelo ocorrido. Nota-se que o uso desses elementos é direcionado para o cliente com uma forma de comprovar que o cliente está errado, e caso não houvesse a resposta por parte dele, o comentário comprovava ser desnecessário e injusto.

Além da violação da polidez negativa, o proprietário também rompe com a estratégia de polidez positiva, já que ele não demonstra estar simpatizado com o cliente, nem tenta estabelecer um contato tão amigável, não houve uma tentativa de aproximação ou saudosismo, uma vez que o intuito da resposta dele, nesse caso, é proteger a sua face, desmontando a face do outro, ou seja, ele seleciona várias perguntas diretas e impositivas, querendo comprometer-se com 0 interlocutor, para que o cliente perca a razão e o bar, com esse fato, ganhe credibilidade. A partir disso, cria-se algumas hipóteses de que a resposta do proprietário deixa visível a sua frustração com o comentário feito pelo cliente acerca de seu estabelecimento, já que o cliente não fez com que a face positiva do proprietário se mantivesse, e também pela desaprovação e desvalorização do bar que ele representa. Na defensiva, o dono do estabelecimento atacou a face negativa de seu interlocutor, com o objetivo de proteger sua própria face, sem o interesse de preservar a face de seu cliente. Configurando, assim, uma atitude de impolidez por parte do proprietário.

No próximo exemplo, o cliente declara que gostou do local, mas não concorda com a cobrança de entrada na área climatizada. A atitude de desacordo 
advinda do cliente é um conflito em potencial, que o proprietário responde com o intuito de justificar o motivo da cobrança que é realizada no ambiente:

Figura 4- Exemplo de ameaça à face negativa do cliente e autoproteção da face positiva do proprietário

Local Guide $\cdot 59$ comentários 38 fotos

tht um mês atrás

Gostei, mas nāo concordo de cobrarem para entrar na área climatizada. Fora isso o ambiente é bem legal

Like

Resposta do proprietário

2 semanas atrás

A cobrança é para manter o karaokê ativo e

atualizado e para manutenção das caixas e mesa de som, microfones, cabos hdmi, tvs e sistema de iluminação! Sabia que as músicas sao compradas e custam em média 10 reais cada uma? Além disso o custo pela climatização existe e é alto. Pois é, Andreza, o valor das entradas existe por isso. $-\theta$

Fonte: Google(2019)

O início da resposta é de teor polido, seguindo as estratégias de polidez positiva que consistem em dar explicações para o fato que incomodou o cliente. $O$ locutor seleciona cada objeto que pertence ao espaço e a influência que esses itens têm sobre o valor cobrado. No desfecho do comentário, mais uma vez, nota-se que o proprietário desse bar se dirige de forma bem direta ao seu cliente, deixando explícita sua imposição "Sabia que as músicas são compradas e custam em média 10 reais cada uma? ". Esse questionamento exige uma resposta do cliente, a fim de dar ênfase ao desconhecimento do cliente em relação aos preços dos itens e às músicas que fazem parte do espaço climatizado, para tanto, ele faz essa provocação ameaçando a face negativa do seu cliente. Por fim, como pode ser visto no desfecho do comentário: "Pois é, Andreza, o valor das entradas existe por isso. "É visível que, com a perda da razão da clientela, ele mantém sua face objetiva, pois o representante, em nome da empresa, objetiva ser valorizado e 
reconhecido, demostrando orgulho, de ser importante especial, elementos que contribuem para a face positiva.

\section{CONSIDERAÇÕES FINAIS}

Nesse trabalho objetivou-se observar as ameaças das faces e as estratégias de polidez usadas pelos proprietários de bares, em resposta às reclamações e críticas que eram feitas pelos clientes que frequentavam os estabelecimentos. As respostas para seus interlocutores, no caso, os clientes, por muitas vezes eram responsáveis pela perda da face positiva dos donos do estabelecimento. Em prol da proteção da face do cliente, como observou-se nas palavras do dono do estabelecimento 1, houve a utilização de algumas estratégias de polidez e preservação das faces, acompanhadas sempre de pedidos de desculpas e oferecimento de recompensa para amenizar o constrangimento da situação ali exposta.

Em contrapartida, observamos também, que o dono do estabelecimento 2 não se preocupou em proteger a face do outro, mas sim de desmontá-la com o intuito da preservação de sua face, contando com uma maior frequência de perda de faces na interação do estabelecimento 2. Nessa interação, não há pedidos de desculpas por parte do proprietário, nem o uso frequente de estratégias de polidez, vê-se um desequilíbrio de preservação das faces, no qual o dono não se preocupa em atender aos desejos do cliente, não oferece recompensas, ou reconhecimento de erros, resultando em uma despreocupação em proteger a face do seu interlocutor, em prol da salvação de sua face.

Em suma, os representantes que falam em nome do estabelecimento, ora buscam romper e salvar a todo instante algumas faces, em um intuito específico, ou em prol do bem-estar do cliente, atribuindo-Ihe razão, ora tiram-lhe a razão, com o objetivo de salvar a sua imagem positiva enquanto estabelecimento comercial. Esse jogo de interação entre locutor e interlocutor recai sobre a preservação da imagem, que se constrói nas relações entre os participantes que vão sendo estabelecidas e isso necessita de uma preservação das faces e das estratégias de polidez em qualquer contexto de comunicação. Com o abandono dessas estratégias, o conflito e desequilíbrio social surgem, causando uma desarmonia nas 
relações sociais. Todos esses elementos aqui apresentados, configuram-se no uso, nas intenções de cada falante, tomando o universo da preservação e ameaças da face como um universo amplo e importante nas interações sociais, tanto reais quanto virtuais, realçando, dessa forma, o caráter dinâmico e interativo da língua.

\section{Referências}

AGUIAR, André Effgen de. A interação face a face: a preservação e ameaça às faces e a estratégias de polidez em entrevistas da Revista Playboy. Cadernos do CNLF Vol. XI, Nº9, CiFEFiL: Rio de Janeiro, 2007.

BAKHTIN, M (1973-1977). A interação verbal. In: BAKHTIN. M. Marxismo e filosofia da linguagem. (tradução: Michel Lahud e Yara Frateschi Vieira) São Paulo: Hucitec, 1995.

BAKHTIN, M. Os Gêneros do discurso. In: Estética da criação verbal. Tradução de Paulo Bezerra. São Paulo: Martins Fontes, 2003.

BARBOSA, M. F. S. O. Impolidez em EAD. Tese (doutorado em linguística). UFRJ, Rio de Janeiro, 2010.

BROWN, P.\& LEVINSON, S. Politness - some universals in language usage. Cambridge: Cambridge University Press, 1978.

GOFFMAN, E. A elaboração da face: uma análise dos elementos rituais da interação social.In: FIGUEIRA, S. (org.) Psicanálise e Ciências Sociais. Rio de Janeiro: Francisco Alves,1980.

GOFFMAN, E. Interactin ritual. New York: Harp e Ruw, 1967.

GOOGLE MAPS. Bar ar livre. Disponível em:< https://www.google.com.br/maps/place/Ar+Livre+Espa\%C3\%A7o+Cultural/@5.0832787,42.7979047,17z/data=!3m1!4b1!4m5!3m4!1s0x78e39e533db7ae1:0xb 965946e900a95ce!8m2!3d-5.083284!4d-42.795716 >. Acesso em: Nov. 2019.

GOOGLE MAPS. Doutores do Chopp. Disponível em: <https://www.google.com.br/maps/place/Doutores+do+Chopp/@5.0673018,42.78 34416,17z/data=!4m5!3m4!1s0x78e3a28a8c25545:0xed3df9009cb5b71e!8m2!3d5.0670293!4d-42.7813924 >. Acesso em: Nov. 2019.

LEVINSON, Stephen C. Pragmática. São Paulo: Martins Fontes, 2007. MARCONDES, Danilo. Filosofia, linguagem e comunicação. São Paulo: Contexto, 1992.

WILSON, Victoria. Motivações pragmáticas. In: MARTELOTTA, Mário Eduardo. Manual de linguística. São Paulo: Contexto, 2011. 